\title{
TUBERCULOSIS MANAGEMENT AT A PEDIATRIC HEMATOONCOLOGY UNIT AFTER INHOSPITAL EXPOSURE TO A CASE WITH ACTIVE DISEASE
}

C. Grasa ${ }^{1}$, D. Blázquez ${ }^{1}$, M. Baro ${ }^{2}$, P. López ${ }^{3}$, L. Prieto ${ }^{1}$, P. Rojo ${ }^{1}$, C. Moraleda ${ }^{1}$, E. FernándezCooke ${ }^{1}$, A. Rubio ${ }^{2}$, C. Liébana ${ }^{4}$, C. Epalza ${ }^{1}$.

${ }^{1}$ Doce de Octubre University Hospital, Pediatric Infectious Diseases, Madrid, Spain. ${ }^{2}$ Doce de Octubre University Hospital, Pediatric HematoOncology,

Background Madrid, Spain. ${ }^{3}$ Doce de Octubre University Hospital, Microbiology, Madrid, Spain. ${ }^{4}$ Doce de Octubre University Hospital, Pediatric Radiology, Madrid, Spain

Risk of tuberculosis (TB) is increased in immunocompromised patients and children. There are no guidelines on how to study paediatric oncological population exposed to TB.

Aim: to describe our experience in the management of hematooncology children exposed to a patient's mother with active TB.

\section{Methods}

Prospective study of hematooncology children with inhospital exposure to TB in a tertiary hospital in Madrid in April 2017.

Tuberculin Skin Test (TST), IGRA (Quantiferon ${ }^{\circledR}$ ) and chest $\mathrm{X}$-ray were performed initially and repeated 10-12 weeks after last exposure.

\section{Conclusions}

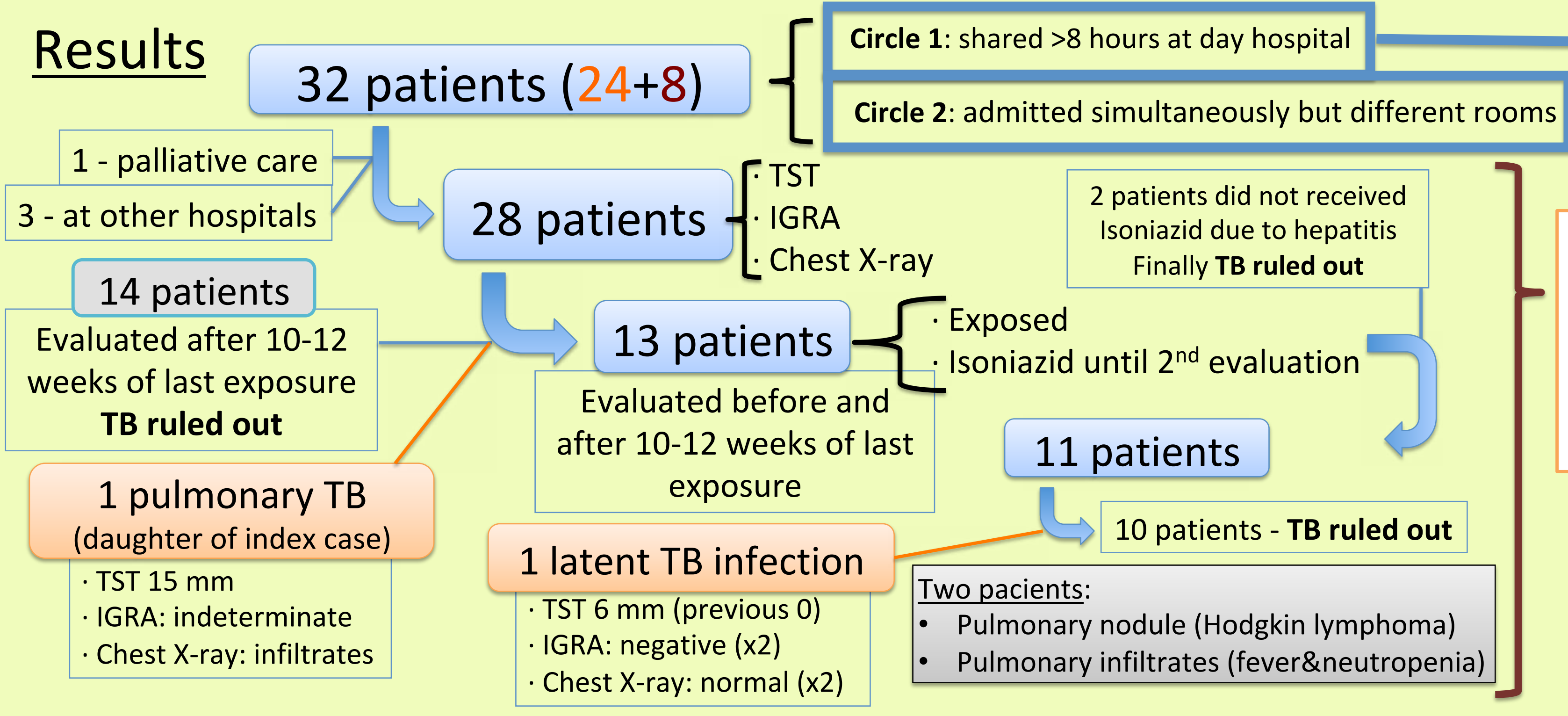

210 hospital activities

84 interviews

April-July 2017

1 pulmonary TB

1 LTBI

- In our study, one oncologic patient presented latent TB infection after inhospital exposure to index case.

- In 2 cases, TB complicated differential diagnosis of pulmonary condition.

- The approach to oncologic children exposed to TB involved a multidisciplinary team and a considerable use of resources in a short time.

Keywords: tuberculosis, hematooncology, tuberculosis exposure, children, immunocompromised, TST 